\title{
Fluoride content and recharge ability of five glassionomer dental
} materials

\author{
Dejan Lj Markovic ${ }^{\dagger 1}$, Bojan B Petrovic ${ }^{* \dagger 2}$ and Tamara O Peric ${ }^{\dagger 1}$
}

Address: ${ }^{1}$ Faculty of Dentistry, Clinic for Paediatric and Preventive Dentistry, Dr Subotica 11, Belgrade, Republic of Serbia and ${ }^{2}$ Dentistry Clinic of Vojvodina, Department for Paediatric and Preventive Dentistry, Hajduk Veljkova 12, Novi Sad, Republic of Serbia

Email: Dejan Lj Markovic - dejanmar@yubc.net; Bojan B Petrovic* - bpetrovicns@yahoo.com; Tamara O Peric - peric@yubc.net

* Corresponding author †Equal contributors

Published: 28 July 2008

BMC Oral Health 2008, 8:21 doi:|0.1| 86/|472-683|-8-2|
Received: 4 November 2007

Accepted: 28 July 2008

This article is available from: http://www.biomedcentral.com/1472-683I/8/2I

(c) 2008 Markovic et al; licensee BioMed Central Ltd.

This is an Open Access article distributed under the terms of the Creative Commons Attribution License (http://creativecommons.org/licenses/by/2.0), which permits unrestricted use, distribution, and reproduction in any medium, provided the original work is properly cited.

\begin{abstract}
Background: The relationship between fluoride content and fluoride release for glass-ionomer cements is not well understood. The aim of this laboratory study was: to determine the fluoride concentrations at the surfaces of glass-ionomer materials with respect to different storage media and different $\mathrm{pH}$ environments; to examine the recharge ability of the materials after $\mathrm{NaF}$ immersion; and to assess the morphological changes at the material surfaces using scanning electron microscope and energy dispersive spectroscopic techniques (SEM/EDS).
\end{abstract}

Methods: Five glass-ionomer materials, Fuji Triage (FT), Fuji II LC (FII), Fuji VIII (FVIII), Fuji IX GP (FIX), and Ketac NI00 (KN), were analyzed in this study. Resin-based fluoride releasing material Helioseal $F(H S F)$ was used as a comparison material. The sample consisted of 120 cured cement disks $(n=20$ disks of each tested material, $10 \times 1.5 \mathrm{~mm}$ ). Five disks of each material were stored in 4 different storage media (I- saline, II- acidic solution $\mathrm{ph}=2.5$, III- acid solution $\mathrm{ph}=5.5$, IV- NaF solution $(\mathrm{c}=500 / / 06)$. After 7 days, two disks of each material were transferred from media I, II and III to the NaF solution for $3 \mathrm{~min}$. EDS analysis was conducted in 3 randomly selected spots of each experimental disk. SEM was used to determine morphological characteristics of the material surface. Differences between the experimental groups have been analyzed using Student's t-test with the level of significance set at $p<0.001$.

Results: FT showed the highest fluoride content at the surface of the material. The lowest amounts of fluoride ions were detected at the surfaces of the FT disks stored at low pH environments, and this difference was statistically significant $(p<0.00 I)$. Glass-ionomers showed significantly higher fluoride concentrations when compared to the HSF $(p<0.00 I)$. After immersion in the $\mathrm{NaF}$ solution, fluoride concentrations at the surfaces of the disks increased when compared with previous storage media (FT>FVIII>KN>FII>FIX). SEM analysis of the surface morphology revealed numerous voids, cracks and microporosities in all experimental groups, except for KN and HSF. More homogenous material structure with more discrete cracks was observed in samples stored at neutral $\mathrm{pH}$ environment, compared to disks stored in acidic solutions.

Conclusion: The tested materials could be considered as promising dental materials with potential prophylactic characteristics due to their relatively high fluoride content, but also the ability to extensively reabsorb fluoride ions, especially in acidic environments. 


\section{Background}

Modern approach to the control of dental caries requires dental materials which possess both restorative and prophylactic characteristics. The anticariogenic behaviour of a dental material has been attributed to its fluoride content [1]. The fluoride content in the material, as well as the amount of released fluoride necessary for "curing" carious lesion and for prevention of secondary caries, have not been well documented. It may be assumed that the content of fluoride should be as high as possible, yet without adverse effects on the physical properties of the material. It has been shown that if a dental material exhibited high fluoride release, it had inferior mechanical properties [2].

Glass-ionomer cements are characterized by acid-base setting reaction, chemical bonding to enamel and dentine, fluoride release, biocompatibility and acceptable aesthetics $[3,4]$. Generally, it can be assumed that a major advantage of glass-ionomers is their potential cariostatic effect [5], due to the fluoride release [4] and antibacterial activity $[5,6]$. Glass-ionomer cements contain 10 to $23 \%$ fluoride [7]. In general it may be supposed that there is a direct relationship between the fluoride present in the cement and the amount of fluoride released [8-10].

Laboratory studies $[1,11]$ clearly demonstrated strong effects of glass-ionomers on caries development and progression. The data collected in these studies suggest that fluoride release from dental materials is dependent on the medium used in the evaluation. Storage at low pH environments accelerates the amount of fluoride released from glass-ionomers, suggesting a strong anticariogenic potential in real clinical situations. However, clinical investigations showed contradictory results with regard to caries development. Many clinical trials reported significantly lower incidence of secondary caries around glassionomers compared with other restorative materials $[1,12]$. Nevertheless, other studies revealed relatively high frequency of secondary caries in relation to failures of glass-ionomer restorations in general dental practice [13$15]$.

Today, there is a variety of glass-ionomer materials available in the market. The purpose of this study was:

- to determine the fluoride concentrations at the surfaces of glass-ionomer materials with respect to different storage media and different $\mathrm{pH}$ environments;

- to examine the recharge ability of the materials after $\mathrm{NaF}$ immersion; and

- to assess the morphological changes at the material surfaces using SEM/EDS.

\section{Methods}

Five glass-ionomer materials, Fuji Triage Capsule (FT, conventional glass-ionomer protection material, GC Int, Tokyo, Japan), Fuji IX GP (FIX, conventional glass-ionomer restorative cement, GC Int), Fuji VIII GP Capsule (FVIII, resin-modified glass-ionomer restorative cement, GC Int), Fuji II LC Capsule (FII, light-cured resin modified glass-ionomer restorative material, GC Int) and Ketac N100 (KN, light-cured nano-ionomer restorative material, $3 \mathrm{M}$ ESPE AG, Seefeld, Germany), were analyzed in this study. Helioseal F (HSF, resin-based fluoride releasing material, Ivoclar Vivadent AG, Schaan, Liechtenstein), was used as a comparison material.

Tested materials were prepared according to the manufacturers' instructions. The capsulated glass-ionomer materials (FT, FII and FVIII) were activated just before mixing, set into the amalgamator, and mixed for 10 seconds at high speed. The mixed capsules were loaded into the capsule applier. The powder and liquid components of the FIX were dispensed onto the pad using the plastic spatula. The powder was divided into 2 equal parts. The first portion was mixed with all the liquid for 10 seconds. The remaining portion was incorporated and mixed thoroughly for 15-20 seconds. Two KN pastes were dispensed onto the mixing pad and mixed together for 20 seconds using the plastic cement spatula until the uniform colour was achieved. HSF was used directly and dispersed with the disposable cannula.

Immediately after mixing the materials were transfered into a cylindrical teflon mould $(10 \times 1.5 \mathrm{~mm})$. During setting, the bottom and top of the moulds were covered by glass plates using hand pressure. Light cured materials (FII, KN, HSF) were photoactivated for 40 seconds with photopolimerisation device (Blue Lex LD-105, Monitex Industrial Co, Taipei, Taiwan). The setting reaction of FT was accellerated with a 40s photo-activation. FVIII and FIX samples were maintained inside the moulds, covered by the matrix, for ten minutes.

After hardening, the specimens were removed from the mould and all discs were submitted to standard polishing under wet conditions using Sof-Lex discs 8691-F (3 M ESPE AG, Seefeld, Germany). After polishing, the disks were transferred to $10 \mathrm{ml}$ of deionized water and stored at $37^{\circ} \mathrm{C}$. The whole sample, consisted of 120 disks ( $\mathrm{n}=20$ disks of each material) was submitted to 4 different storage media ( $\mathrm{n}=5$ disks of each material per each storage medium). The storage media were prepared as follows:

- medium I - $10 \mathrm{ml}$ of saline

- medium II - $10 \mathrm{ml}$ of acidic solution at pH 2.5 made of a $0.1 \mathrm{M}$ lactic acid solution acidified with $\mathrm{HCl}$; 
- medium III - $10 \mathrm{ml}$ of acidic solution at pH 5.5 made of $50 \mathrm{mmol} / \mathrm{l} \mathrm{KCl}$ titrated to $\mathrm{pH} 5.5$ with concentrated $\mathrm{HCl}$

- medium IV - NaF solution ( $c=500$ ppm $)$

Disks were stored in four different storage media at $37^{\circ} \mathrm{C}$ for 7 days. After that period, 2 disks of each material were transferred from media I, II and III to the NaF solution (containing $500 \mathrm{ppm}$ of F). Those samples were immersed for $3 \mathrm{~min}$ to simulate the fluoride ion recharge.

The surface of each disk was rinsed with $2 \mathrm{ml}$ of deionized water. The specimens were mounted on aluminium stubs, sputter-coated with gold (Bal-Tec SCD 005 Sputter Coater, Bal-Tec AG, Balzers, Liechtenstein), and then examined using scanning electron microscope (Jeol JSM-6460LV, Jeol Industries Ltd., Tokyo, Japan) equipped with energy dispersive spectrometer (SEM/EDS). In each disk, SEM/ EDS analysis was performed in three randomly selected spots. Quantitative changes of the material surface and the recharge ability after the $\mathrm{NaF}$ treatment were evaluated using EDS. SEM was used to determine the effects of different storage media and different $\mathrm{pH}$ environments on morphological characteristics of cured cement disks. The criteria for evaluation included the presence of cracks and micropores at the surface of the material.

Descriptive statistical analyses were primarly performed. Differences between the experimental groups has been analyzed using Student's t-test, with the level of significance set at $\mathrm{p}<0.001$.

\section{Results}

Surface concentration of fluoride in relation to the storage medium

A total of 84 disks were analyzed ( 3 disks of each material from media I, II and III, and 5 disks of each material from medium IV). Table 1 shows average values of the fluoride surface concentrations (in mass $\%$ of $\mathrm{F}-\mathrm{wt} \%$ ) in relation to storage medium. In all storage media, surfaces of glassionomer materials showed significantly higher fluoride concentrations when compared to the HSF ( $p<0.001$ Student's t-test). The lowest concentrations of fluoride ions were detected at the surfaces of disks stored in acidic environment at $\mathrm{pH}=2.5$. Significant differences $(\mathrm{p}<0.001$ Student's t-test) in fluoride concentrations were observed in relation to storage media (IV>I $>I I>I I I)$.

\section{The effect of fluoride immersion}

The effect of $\mathrm{NaF}$ immersion on fluoride content at the surface of the glass-ionomer material was evaluated in 36 disks ( 2 disks of each material from media I, II, and III). For all tested materials, fluoride concentrations at the surfaces of the disks increased when compared with the previous storage media (table 2 ).

\section{SEM analysis of the surface morphology}

SEM showed morphological differences in all materials, in the samples stored at pH 2.5, pH 5.5 and in saline (figure 1). More homogenous material structure with more discrete cracks was observed in samples stored at neutral $\mathrm{pH}$ environment. Destruction of the material surface was evident in samples stored at $\mathrm{pH}$ 2.5. SEM analysis revealed the presence of a large number of voids, cracks and microporosities in FT, FII, FVIII and FIX specimens at $\mathrm{pH} 2.5$, yet they were not detected in $\mathrm{KN}$ and HSF specimens.

\section{Discussion}

After more than 30 years of use, glass-ionomer materials continue to be popular for different indications in contemporary dentistry. Fluoride is an essential component of contemporary dental materials, including glass-ionomer cements. Fluoride is used as a flux during glass manufacture with the specific purpose of leaching fluoride into the surrounding tissues in order to provide caries prevention or secondary caries inhibition. Glass ionomers release significant amounts of fluoride into tooth structure, as well as into the oral environment. During the caries process, an acidic environment attacks dental tissues as well as the glass-ionomer cement [16]. In the present study two conventional glass-ionomers (FII and FIX), two resin modified glass-ionomers (FII and FVIII), and a

Table I: Surface concentration of fluoride in relation to the storage medium.

\begin{tabular}{|c|c|c|c|c|c|c|c|c|}
\hline & \multicolumn{2}{|c|}{ medium I } & \multicolumn{2}{|c|}{ medium II } & \multicolumn{2}{|c|}{ medium III } & \multicolumn{2}{|c|}{ medium IV } \\
\hline & $w t F(\%)$ & SD & wt $F(\%)$ & $\mathrm{SD}$ & wt $F(\%)$ & SD & wt F(\%) & SD \\
\hline FT & $10.0^{a, b, c, d}$ & 0.56 & $3.8^{\mathrm{a}, \mathrm{b}, \mathrm{c}, \mathrm{d}}$ & 0.25 & $4.8^{a, b . c . d}$ & 0.20 & $15.6^{a, b, c, d}$ & 0.40 \\
\hline FII & $7 \mathrm{~A}, \mathrm{~B}, \mathrm{C}, \mathrm{D}$ & 0.25 & $4.6 \mathrm{~A}, \mathrm{~B}, \mathrm{D}$ & 0.22 & $4.6 \mathrm{~A}, \mathrm{C}, \mathrm{D}$ & 0.16 & $7.8 \mathrm{~A}, \mathrm{~B}, \mathrm{C}, \mathrm{D}$ & 0.26 \\
\hline FVIII & $10.4^{x, y \cdot w . z}$ & 0.30 & $4.8^{x, y, w, z}$ & 0.26 & $6.4^{x, y, w, z}$ & 0.39 & $11.5^{x, y, w, z}$ & 0.52 \\
\hline $\mathrm{FIX}$ & $10 .\left.\right|_{X, Y, W, Z}$ & 0.49 & $8.2^{X, Y, W, Z}$ & 0.56 & $9.6 X, Y, W$ & 0.39 & $9.5^{X, Y, Z}$ & 0.42 \\
\hline $\mathrm{KN}$ & $7.6^{1,2,3,4}$ & 0.39 & $2.6^{1,2,4}$ & 0.46 & $2.5^{1,3,4}$ & 0.35 & $8^{1,2,3,4}$ & 0.65 \\
\hline HSF & I. $4^{1, \mathrm{IIII}, \mathrm{IV}}$ & 0.39 & $1.2^{11, \mathrm{IV}}$ & 0.27 & II,III,IV & 0.26 & $2.5^{5, I I I, I I I, I V ~}$ & 0.48 \\
\hline
\end{tabular}

The F concentrations (wt\%); $n=3$ disks for media I, II, III, $n=5$ disks for medium IV; SD; same superscripts indicate average values with statistically significant differences $(p<0.001)$; 
Table 2: The effect of $\mathrm{NaF}$ immersion.

\begin{tabular}{|c|c|c|c|c|c|c|}
\hline & \multicolumn{2}{|c|}{ Disks previously stored in medium I } & \multicolumn{2}{|c|}{ Disks previously stored in medium II } & \multicolumn{2}{|c|}{ Disks previously stored in medium III } \\
\hline & $w t F(\%)$ & SD & wt $F(\%)$ & SD & wt $F(\%)$ & SD \\
\hline $\mathrm{FT}$ & 15.7 & 0.37 & 15.5 & 0.31 & 15.5 & 0.20 \\
\hline FII & 7.8A,B.C & 0.25 & $8.5 \mathrm{~A}, \mathrm{~B}$ & 0.36 & $8.25 \mathrm{~A}, \mathrm{C}$ & 0.27 \\
\hline FVIII & $12 . \mid x, z$ & 0.37 & $12.5 y, z$ & 0.37 & $10.5^{x, y, z}$ & 0.37 \\
\hline FIX & $11.4^{x, Z}$ & 0.37 & $11.8^{Y, Z}$ & 0.37 & $10.5^{X, Y, Z}$ & 0.37 \\
\hline $\mathrm{KN}$ & 8.2 & 0.69 & 8.2 & 0.52 & 8 & 0.70 \\
\hline $\mathrm{HSF}$ & 2.5 & 0.44 & 2.67 & 0.52 & 2.75 & 0.72 \\
\hline
\end{tabular}

The $\mathrm{F}$ concentrations (wt\%); $\mathrm{n}=2$ disks; SD; same superscripts indicate average values with statistically significant differences $(p<0.00 \mathrm{I})$.

nano-ionomer $(\mathrm{KN})$ were evaluated. Fluoride releasing resin based fissure sealant (HSF) was used as comparison material. The materials were chosen as being widely used in contemporary dental practice.

The extended use of experimental models for glass-ionomers evaluation and the extrapolation of the in vivo performance of materials based on the results obtained from laboratory tests have raised numerous concerns on the clinical relevance of laboratory testing protocols [17]. The present study is preliminary investigation limited on several distinct parameters. Only controlled clinical trials, as well as more complex experimental studies comprising large number of factors that may influence the properties of dental materials in real clinical situations could provide more valid conclusions.

The majority of the research into release and uptake of fluoride ions have utilised analysis of ion concentrations in solutions after glass-ionomer immersion [4,19-21]. Useful information have been obtained about the influence of the initial glass-ionomer composition on the removal of ions from solution and their subsequent re-release pattern. However, this approach provides modest information about the morphological and compositional changes that occur in the material during immersion.

Great differences in fluoride release between various materials have been described [22]. However, the relationship between fluoride content and fluoride release for glass-ionomer cement is not well understood. Kuhn and Wilson [23] indicated the existence of three mechanisms concerning fluoride release from glass-ionomers: superficial rinse, diffusion through pores and micro-fractures and finally mass diffusion. The fluoride content at the surface of the glass-ionomer material is an important parameter in quantifying the recharge ability of the glassionomer. Hadley has demonstrated, using depth profiling, that the concentration of fluoride maximised at the surface of the samples [24].
The importance of the knowledge of fluoride release in different storage media has increased in the last years. In a real clinical situation, during the caries attack, acidogenic bacteria create an acid micro-environment that may modify cement's properties $[25,26]$. The model used in the present study focused on assessment of quantitative and qualitative changes at the surfaces of different glass-ionomer materials.

In the first part of the experiment the fluoride concentration at the surface of the materials with regards to different storage media was evaluated. We hypothesized that different storage media and different $\mathrm{pH}$ environments significantly affect the fluoride concentration at the material surface and the rate of fluoride release from a glass-ionomer cement. The quantity of released fluoride was found to be proportional to the fluoride content of the glass-ionomer and other fluoride containing dental materials $[27,28]$. That is why the fluoride concentration was used as a parameter for anticipation of fluoride release in the present study. The fluoride content observed in this study appeared to be significantly lower, compared to some previous investigations and the claims of the manufacturers [7]. Value of the highest fluoride content measured was $19 \%$. The reasons for this discrepancy may be found in the experiment design, but also in the relatively low sensitivity of the EDS analysis, which is a semiquantitative analytical method. Results obtained in this study clearly show that fluoride concentration at the material surface is strongly dependent on storage medium for all tested materials. Important differences between tested materials concerning fluoride concentration were recorded. FT and $\mathrm{KN}$ exhibitted the lowest amounts of fluoride in acidic environment compared to the baseline fluoride concentrations observed in saline. In fact, FT released greater amount of fluoride compared to other tested materials. FT, FVIII and FIX exhibited lower amount of fluoride at $\mathrm{pH}=2.5$ than at $\mathrm{pH}=5.5$ or $\mathrm{pH}=7$. Results of the present experimental study are in agreement with finding that glass-ionomer releases more fluoride when the environ- 


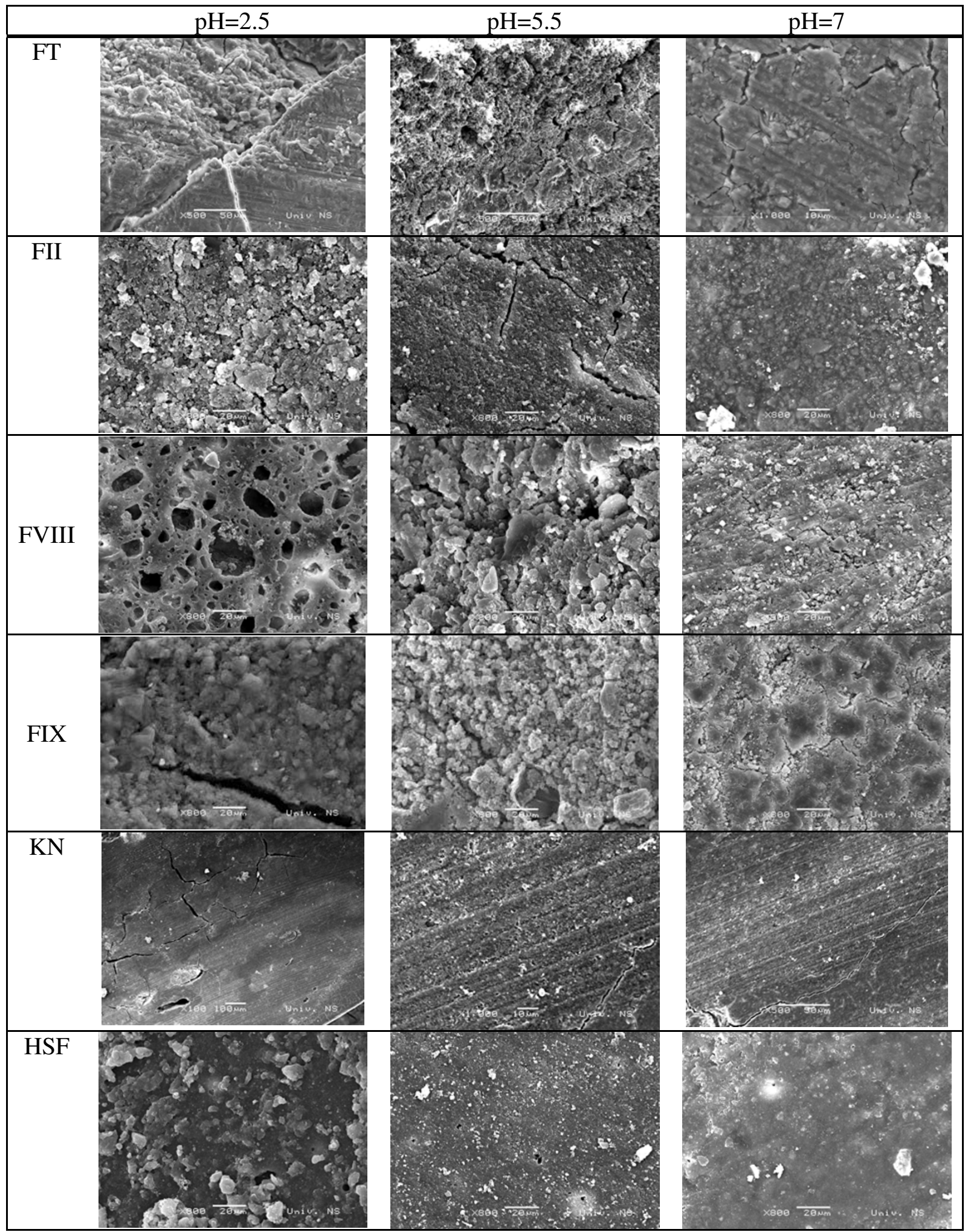

Figure I

Surface morphology in relation to storage media (SEM images of tested materials at 500x-1000x magnification). 
ment was at lower $\mathrm{pH}$, leaving less fluoride content at the surface of the material stored at the acidic solution, thus providing the highest amount of fluoride when it is most needed to prevent secondary caries [7].

The ability to take up and re-release ions from solution is an important asset of glass ionomer cements, which may allow their application as 'rechargeable reservoirs' for the distribution of ions, including fluoride [21]. Despite the substantial number of researches aimed at establishing the mode of fluoride uptake and re-release [29], the underlying mechanism remains unclear. Most of the researches into fluoride ion uptake have utilized analysis of ion concentrations in solution before and after GIC immersion $[1,8,19,21,22,29]$. In the second part of the present study, the ability of fluoride treatment was tested through immersion of samples into $\mathrm{NaF}$ solution containing $500 \mathrm{ppm}$. The main objective was to determine the fluoride absorption ability of the material stored under the different conditions. In agreement with previous studies, the present results showed that exposure of glass-ionomer materials, as well as resin- based fluoride releasing fissure sealant to a solution containing fluoride allows the materials to take up fluoride. Fluoride levels increased to five times more (FT) after treatment of glass- ionomer specimens with $\mathrm{NaF}$ solutions. The major increase in fluoride content was observed in the disks previously stored in acidic solution. This finding is in line with the previous study which showed that the absorption ability decreases with increase of $\mathrm{pH}$ values [22]. Evaluation of ion content at the surface of the material provides usefull information about the influence of the initial material composition on the ion sorption from the solution.

There are some shortcomings of the present experimental model that must be taken into account when comparing results with the similar studies, particularly when extrapolating these results in real clinical situations. Fluoride release was quantified through changes of fluoride concentrations at the surfaces of the materials tested, while the actual fluoride release from glass-ionomers into different storage media has not been obtained. Further on, surface of the material was the central point in the present investigation, without sufficient evidence that the changes at the material surface can represent the changes in the entire restoration.

The SE photomicrographs obtained in this study showed that, regardless of the chemical composition, both conventional (FT and FIX) and resin-modified glassi-onomers (FII and FVIII) presented voids, cracks and microporosities at the disk surface. SEM examination revealed a similar morphological surface pattern to each other. It has been shown that scanning electron microscopy is not a reliable method for assessment of glass-ionomer cements, since glass-ionomers are sensitive to SEM preparation techniques, and the cracks could be produced during specimen processing for SEM analysis [31]. It is possible that there may be some artifacts in the present microstructures of the glass-ionomers observed with the SEM, and future microstructural studies should employ a replica technique in order to capture the changes at the material surface in relation to storage media more precisely. On the other hand, SEM analysis provided direct visibility of the changes at the material surface in relation to storage media. SEM analysis appears to be an efficient and acceptable method of examining such features as surface topography, filler size and distribution, interface adhesion and porosity [32-36]. SEM analysis showed evidence of differences in surface morphology. The presence of more fractures, voids and microporosites were observed in conventional (FT and FIX) and resin-modified glass-ionomers (FII and FVIII) after storage in acidic environment at $\mathrm{pH}=2.5$. SEM analysis of the specimens stored at $\mathrm{pH}=5.5$ failed to show clear evidence of differences in surface morphology between the tested materials, although the presence of more fractures at the disks stored in solution with $\mathrm{pH} 5.5$ compared to specimens stored in saline was observed in both conventional and resin-modified glassionomers. In conclusion, taking into account the limitations of the methodology employed, from SEM images it is observed that an acid environment is related to the degradation of glass-ionomers according to the results of the recent studies [37]. It is also clear that fluoride release is related to GIC degradation. On the contrary, nano-ionomer material (KN), and resin-based fissure sealant (HSF) appear to be resistant to storage in different $\mathrm{pH}$ environment, since no morphological changes at the surface of these materials in relation to storage media could not be observed.

Results of the present study confirm that glassi-onomers are not very resistant to external agents and in low $\mathrm{pH}$ environments they are undergoing noticeable destruction. On the other hand, destruction of the material surface is followed by extensive fluoride release necessary to resist the caries attack.

It goes without saying that conclusions from laboratory studies may not be comparable with studies in-vivo. In addition, it is important to take into consideration that different methodologies used in the studies, including specimen size, media used to measure fluoride release and uptake, quantity of media used to measure fluoride as well as different methods to measure fluoride release, are responsible for the numerous differences. Thus, comparisons between the materials should be made considering behaviour of materials rather than the absolute amount of released and uptaken fluoride (in absolute terms). 


\section{Conclusion}

1. The fluoride concentrations at the surfaces of glass-ionomer based materials is under influence of storage media and $\mathrm{pH}$ environments.

2. All tested materials exhibit the property of recharging the fluoride surface concentrations at the material surfaces after fluoride immersion. The increased recharge rate is related to decreasing $\mathrm{pH}$.

3. Acidic environment affects the material surface, resulting in less homogenous structure, with voids, gaps and microporosities. The amount of cracks and microporosities correlates with decreasing $\mathrm{pH}$.

4. All tested materials possess relatively high fluoride content and the ability to extensively reabsorb fluoride ions, especially in low $\mathrm{pH}$ environments.

\section{Competing interests}

Dejan Markovic, Bojan Petrovic and Tamara Peric declare that they have no competing interests. Prof. Dejan Markoviæ is the Key Opinion Leader for GC in Serbia. In past five years he received some funding from GC for various scientific activities. GC is not financing this investigation (including the article-processing charge). The authors do not hold any stocks or shares in an organization that may in any way gain or lose financially from the publication of this manuscript. The authors as well do not hold or currently applying for any patents relating to the content of the manuscript, and never had received fundings from an organization that holds or has applied for patents relating to the content of the manuscript. There are no nonfinancial competing interests (political, personal, religious, academic, ideological, intellectual, commercial or any other).

\section{Authors' contributions}

All authors contributed equally to this work. DM, TP and $\mathrm{BP}$ have come together to the final conception and design of the study. BP carried out the study at the Department for Scanning Electrone Microscopy, Faculty of Sciences, Novi Sad, and analysed the results. DM, TP and BP have evaluated the morphological changes in material surface together. DM supervised the manuscript, and all authors have given final approval of the version to be published.

\section{Acknowledgements}

The authors are very grateful to Mr Milos Bokorov from the Department for Scanning Electrone Microscopy, Faculty of Sciences, Novi Sad, who contributed to this study with devotion and professionalism regarding specimens preparation, and technical conduction of the SEM/EDS analysis.

\section{References}

I. Wiegand A, Buchalla W, Attin T: Review on fluoride-releasing restorative materials- fluoride release and uptake characteristics, antibacterial activity and influence on caries formation. Dent Mater 2007, 23(3):343-362.
2. Kavaloglu CS, Cildir S, Sandalli N: Compressive strength, surface roughness, fluoride release and recharge of four new fluoride-releasing fissure sealants. Dent Mater J 2007, 26(3):335-4I.

3. Yip HK, Tay FR, Ngo HC, Smales RJ, Pashley DH: Bonding of contemporary glass ionomer cements to dentin. Dent Mater 200 I, I 7:456-470.

4. Vermeersch G, Leloup G, Vreven J: Fluoride release from glassionomer cements, compomers and resin composites. J Oral Rehab 200I, 28(I):26-32.

5. Dunne SM, Goolnik JS, Millar BJ: Caries inhibition by a resin modified and conventional glass ionomer cement in vitro. J Dent 1996, 24(I-2):91-94.

6. Featherstone JDB: Prevention and reversal of dental caries: role of low level fluoride. Community Dent Oral Epidemiol 1999, 27:31-40.

7. Frencken JE, Holmgren CJ: Atraumatic restorative treatment for dental caries. STI Book b v Nijmegen 1999.

8. Forsten F: Fluoride release and uptake by glass-ionomers. Scand J Dent Res 199I, 99:24I-245.

9. Francci C, Deaton TG, Arnold RR, Swift EJ, Perdigao J, Bewden JW et al: Fluoride release from restorative materials and its effect on dentin demineralization. J Dent Res 1999, 78: 1647-54.

10. Perrin C, Persin M, Sarrazin J: A comparison of fluoride release from four glass ionomer cements. Quintessence Int 1999, 25(9):603-8.

II. Randall RC, Wilson NH: Glass-ionomer restoratives: a systematic review of a secondary caries treatment effect. J Dent Res 1999, 78(2):628-37.

12. Frost PM: An audit on the placement and replacement of restorations in a general dental practice. Prim Dent Care 2002, 9(I):3 I-6.

13. Mjor IA: Glass-ionomer cement restorations and secondary caries: a preliminary report. Quintessence Int 1996, 27(9):58|-582.

14. Mjor IA: The reasons for replacement and the age of failed restorations in general dental practice. Acta Odontol Scan 1997, 55:58-63.

15. Wilson NHF, Burke FJT, Mjor IA: Reason for placement and replacement of restorations of direct restorative materials by a selected group of practitioners in the United Kingdom. Quint Int 1997, 28:245-8.

16. Carey CM, Spencer M, Gove RJ, Eichmiller FC: Fluoride Release from a Resin-modified Glass-ionomer Cement in a Continuous-flow System: Effect of pH. J Dent R 2003, 82(I 0):829-832.

17. Papagiannoulis $L$, Kakaboura $A$, Eliades $G$ : In vivo vs in vitro anticariogenic behavior of glass-ionomer and resin composite restorative materials. Dent Mater 2002, I 8(8):56I-9.

18. Savarino L, Cervellati M, Stea S, Cavedagna D, Donati ME, Pizzoferrato $A$ : In vitro investigation of aluminum and fluoride release from compomers, conventional and resinmodified glass-ionomer cements: a standardized approach. J Biomater Sci Polym 2000, I I :289-300.

19. Hsu HM, Huang GF, Chang HH, Wang YL, Guo MK: A continuous flow system for assessing fluoride release/uptake of fluoridecontaining restorative materials. Dent Mater 2004, 20(8):740-749.

20. De Schepper EJ, Berry EA, Cailleteauand JG, Tate WH: A comparative study of fluoride release from glass ionomer cements. Quint Int 1991, 22:215-220.

21. Hatibovic-Kofman S, Koch G: Fluoride uptake and release from a glass-ionomer. Swed Dent J I 991, I 5:253-258.

22. Gandolfi MG, Chersoni S, Acquaviva GL, Piana G, Prati C, Mongiorgi $\mathrm{R}$ : Fluoride release and absorption at different $\mathrm{pH}$ from glassionomer cements. Dent Mater 2006, 22(5):44I-9.

23. Kuhn AT, Wilson AD: The dissolution mechanism of silicate and glass-ionomer cements. Biomaterials 1985, 6:378-382.

24. Hadley PC, Milella E, Cerardi C, Hill RG, Bilington RW: Distribution of fluoride in glass-ionomer cement determined using SIMS. Biomaterials 200I, 22: I563-I569.

25. Okada K, Tosaki S, Hirota K, Hume WR: Surface hardness change of restorative filling materials stored in saliva. Dent Mater 200I, I 7:34-9.

26. Auschill TM, Artweiler NB, Netuschil L, Brecx M, Reich E, Sculean A et al: Spatial distribution of vital and dead microorganisms in dental biofilms. Arc Oral Biol 200I, 46:47I-6. 
27. Guida A, Hill RG, Towler MR, Eramo S: Fluoride release from model glass ionomer cements. J Mater Sci Mater Med 2002, 13(7):645-9.

28. Helvatjoglu-Antonides M, Karantakis P, Papadogiannis Y, Kapetanios $\mathrm{H}$ : Fluoride release from restorative materials and a luting cement. J Prosthet Dent 200I, 86: I56-64.

29. Hadley PC, Bilington RW, Pearson G]: Effect of monovalent ions in glass ionomer on their uptake and re-release. Biomaterials 1999, 20:891-897.

30. Forsten L: Fluoride release and uptake by glass-ionomers and related materials and its clinical effect. Biomater 1998, 19:503-508.

31. Milicich G: A resin impression SEM technique for examining the glass-ionomer cement chemical fusion zone. Journal of Microscopy 2005, 21 7:44-48.

32. Xie D, Brantley WA, Culbertson BM, Wang G: Mechanical properties and microstructures of glass-ionomer cements. Denl Mater 2000, 17:129-138.

33. Øilo G: Characterization of glass ionomer filling materials. Dent Mater 1988, 4: I29-33.

34. Nakajima H, Watkins JH, Arita K, Hanaoka K, Okabe T: Mechanical properties of glass ionomers under static and dynamic loading. Dent Mater 1996, 12:30-7.

35. Lloyd $\mathrm{CH}$, Adamson M: The development of fracture toughness and fracture strength in posterior restorative materials. Dent Mater 1987, 3:225-31.

36. Swift EJ Jr, Dogan AU: Analysis of glass ionomer cement with use of scanning electron microscopy. J Prosthet Dent 1990, 64:167-74.

37. Mohamed-Tahir MA, Yap AUJ: Effects of pH on the surface texture of glass ionomer based/containing restorative materials. Oper Dent 2004, 29:586-91.

\section{Pre-publication history}

The pre-publication history for this paper can be accessed here:

http://www.biomedcentral.com/1472-6831/8/21/prepub

Publish with BioMed Central and every scientist can read your work free of charge

"BioMed Central will be the most significant development for disseminating the results of biomedical research in our lifetime. "

Sir Paul Nurse, Cancer Research UK

Your research papers will be:

- available free of charge to the entire biomedical community

- peer reviewed and published immediately upon acceptance

- cited in PubMed and archived on PubMed Central

- yours - you keep the copyright 